\title{
Sequence of Molecular Events during the Maturation of the Developing Mouse Prefrontal Cortex
}

\author{
Shuhei Ueda ${ }^{a}$ Minae Niwa $^{c}$ Hiroyuki Hioki ${ }^{b}$ Jaerin Sohn ${ }^{b}$ Takeshi Kaneko $^{b}$ \\ Akira Sawa ${ }^{c}$ Takeshi Sakurai ${ }^{a}$ \\ ${ }^{a}$ Medical Innovation Center, and ${ }^{b}$ Department of Morphological Brain Science, Kyoto University Graduate \\ School of Medicine, Kyoto, Japan; ' Department of Psychiatry, Johns Hopkins University School of Medicine, \\ Baltimore, Md., USA
}

\section{Key Words}

qRT-PCR · Synapse · Inhibitory neurons · Dopamine ·

Glutamate $\cdot$ Myelination

\begin{abstract}
Recent progress in psychiatric research has accumulated many mouse models relevant to developmental neuropsychiatric disorders using numerous genetic and environmental manipulations. Since the prefrontal cortex (PFC) is essential for cognitive functions whose impairments are central symptoms associated with the disorders in humans, it has become crucial to clarify altered developmental processes of PFC circuits in these mice. To that end, we aimed to understand a sequence of molecular events during normal mouse PFC development. Expression profiles for representative genes covering diverse biological processes showed that while there were little changes in genes for neuroreceptors and synaptic molecules during the postnatal period, there were dramatic increases in the expression of myelin-related genes and the parvalbumin gene, peaking at postnatal day (P)21 and P35, respectively. The timing of the peaks is different from that observed in the striatum. Furthermore, the evaluation of the circuitry maturation by measuring extracellular glutamate in the PFC revealed that sensitivity to an
\end{abstract}

NMDA antagonist did not become an adult-like pattern till P56, suggesting that some of the maturation processes continue till P56. The trajectory of molecular events in PFC maturation described here should help us to characterize how the processes are affected in disease model mice, an important first step for translational research.

(c) 2015 S. Karger AG, Basel

\section{Introduction}

The prefrontal cortex (PFC) is a pivotal brain region for executive cognitive functions, including working memory, planning, reasoning, and decision-making [1]. Acquisition of these higher brain functions depends on the development and maturation of the PFC, which take decades to complete in humans [2-4]. PFC development and maturation involve diverse biological processes, namely synapse formation, local circuitry formation, connectivity among several brain regions through long projections (network formation), the formation of neuromodulation networks, activity-dependent synaptic modulation and plasticity, and myelination. These processes should proceed in a coordinated and sequential manner, each process affecting others [5].

\section{KARGER 125}

C 2015 S. Karger AG, Base

2296-9209/15/0012-0094\$39.50/0

E-Mail karger@karger.com

www.karger.com/mnp
Takeshi Sakurai, MD, PhD

Medical Innovation Center

Kyoto University Graduate School of Medicine

53 Kawahara-cho, Shogoin, Sakyo-ku, Kyoto 606-8507 (Japan)

E-Mail sakurai@tk.med.kyoto-u.ac.jp 
Impairments in cognitive functions are central symptoms associated with developmental neuropsychiatric disorders such as schizophrenia [6]. As a potential etiology of schizophrenia, developmental hypothesis has been proposed, in which combinations of genetic and environmental factors cause alterations in developmental processes that serve as the biological basis for pathogenesis of the disorder $[7,8]$. In schizophrenia, PFC development is presumed to be disrupted, resulting in cognitive impairments even before the onset of the disorder (the socalled prodromal period) [9]. Brains with schizophrenia also show changes associated with many systems including dopamine, glutamate, GABA, and myelin [10].

Recent human genetics studies have provided us with a list of candidate genes involved in disorders like autism and schizophrenia [11-13]. Subsequently, a number of mouse models with modification of those genes have been developed, many of which display behavioral phenotypes relevant to human psychiatric disorders [14-16]. To understand the biological processes affected in these animals that can be translated into cognitive impairments in the disorders in humans [17], it is crucial to understand a developmental trajectory of the PFC in mice [5]. In the present study, we characterized a sequence of molecular events in the developing mouse PFC using gene expression profiles as molecular signatures for developmental processes.

\section{Materials and Methods}

Animals

All animals used in this study were treated in accordance with the guidelines by the Animal Care and Use Committee of Kyoto University and Johns Hopkins University. Wild-type C57BL/6JJcl mice were purchased from CLEA Japan (Tokyo, Japan) for qRTPCR and from Charles River Laboratories (Wilmington, Mass., USA) for in vivo microdialysis. PV/myrGFP-LDLRct mice in the C57BL/6JJcl background that express myristoylated green fluorescence protein (GFP) fused with the low-density lipoprotein receptor (LDLR) cytoplasmic region under the parvalbumin (PV) gene promoter were previously described [18].

\section{RNA Preparation and $q R T-P C R$ Analysis}

Brain regions of interest were identified using the atlas of Paxinos and Franklin [19] and collected from 1-mm-thick brain slices using a tissue puncher with a diameter of $1.2 \mathrm{~mm}$ (online suppl. fig. 1, www.karger.com/doi/10.1159/000430095). Total RNAs from the medial PFC and striatum were extracted using the RNeasy Mini kit (QIAGEN, Hilden, Germany), and cDNAs were synthesized using the ReverTra Ace qPCR RT Master Mix (TOYOBO, Osaka, Japan). qRT-PCR was performed using the 7900 HT Fast Real-Time PCR System or ViiA ${ }^{\text {TM7 }}$ Real-Time PCR System (both Applied Biosystems, Waltham, Mass., USA) with the THUNDERBIRD Probe
Table 1. List of primers and universal probe sets used for qRT-PCR

\begin{tabular}{lll}
\hline Gene $\quad$ Forward/reverse primer & Universal \\
& probe No.
\end{tabular}

Control

Gapdh gccaaaagggtcatcatctc/cacacccatcacaaacatgg 29

Neuroreceptors

Gria1 agggatcgacatccagagag/tgcacatttcctgtcaaacc 62

Gria2 cagtttcgcagtcaccaatg/acccaaaaatcgcatagacg $\quad 32$

Gria3 agccgtgtgatacgatgaaa/caaggtttacaggcgttcct 31

Gria4 ctgccaacagttttgctgtg/aaatggcaaacaccctcta 48

Grin1 ggagacgttgctggaggag/tcttggttcctgggtcaaac 13

Grin2a ccttgtggagacaggaatca/aaggggaaacagtgccatta 80

Grin $2 b$ aatacagagaacgaaacctcgact/aaagcgcattgctttcgtat 38

Drd1a tctggtttacctgatccetca/gcctcctccctcttcaggt 82

$\operatorname{Drd2} \quad$ gtcaacaccaagcgtagcag/tcagggtgggtacagttgc 21

Drd4 ccatcagcgtggacaggt/acacaccactggcgaagc 66

Drd5 tcctggtgtgcttatgctttc/tcagctaagaatcgtttggtttc 18

Synaptic components

Psd95 ggcgcacaagttcattgag/tgagacatcaaggatgcagtg 83

Shank3 tggttggcaagagatccat/ttggccccatagaacaaaag 1

Fmr1 cacagagacgaactcagtgattg/ctctgcgcaggaagctct 6

Cyfip1 ccacacgctacaactacacca/gcctttgatcatggcaatc 22

Nrcam cacaccttaatcccacca/ccaccagatgatccttgtca 5

Nfasc ccaaagaagaagatggctcatt/catagtccaccaggctgtca 18

Cntn1 gagcaaagggacggagtg/ccaagctaccatcttcccata 84

Cntn2 gggagcctgtgctacaagac/gctttccagtagcgaatctca 88

Cntnap1 gctggggctactacggttg/ccagagaccgtgcatacaga 17

Cntnap2 cctacaaagatcacctgccagt/tgagccttgtcggtcagtatc 77

GABAergic interneurons

Gad1 atacaacctttggctgcatgt/ttccgggacatgagcagt 27

PV ggcaagattggggttgaag/agcagtcagcgccacttag 83

Sst cccagactccgtcagtttct/gggcatcattctctgtctgg 53

Vip gcctctcttggaccacctt/ctccttcaaacggcatcct 42

Oligodendrocyte/myelin

Sox10 ctgtctcccatctcctgtc/aaataaaggggcagcgatgt 26

Olig2 agaccgagccaacaccag/aagctctcgaatgatccttcttt 21

Plp1 gcatttgcccaaatctgc/gcgaaagatccttgctttga 7

Cldn11 gcctggagtggccaagta/agccagcagaataaggagca 20

Cnp1 cgctggggcagaagaatac/aaggccttgccatacgatct 10

Mag tctaccoggattgtcactg/gcagcctcctctcagatcc $\quad 45$

qPCR Mix (TOYOBO) and Universal ProbeLibrary (Roche, Indianapolis, Ind., USA) [20]. Primers were designed using the Universal ProbeLibrary Assay Design Center (Roche; table 1). All samples were run in triplicate. Relative gene expression levels to the level at postnatal day $(\mathrm{P}) 7$ were calculated using the $\Delta \Delta \mathrm{Ct}$ method normalized with Gapdh as an endogenous control gene.

\section{Histology}

Mice were anesthetized with a mixture of ketamine and xylazine and transcardially perfused with phosphate-buffered saline (PBS) followed by $4 \%$ paraformaldehyde in PBS. The isolated 
brains were postfixed overnight, and $50-\mu \mathrm{m}$-thick coronal sections were prepared using a vibratome VT1200S (Leica Biosystems, Buffalo Grove, Ill., USA). The sections were washed with PBS and mounted with VECTASHIELD mounting medium with DAPI (Vector Laboratories, Burlingame, Calif., USA). Fluorescent images were acquired using an all-in-one fluorescence microscope BZ-9000 (KEYENCE, Osaka, Japan). We counted all GFP-positive cells in both layer $2 / 3$ and layer $5 / 6$ of area 24 in all sections ranging from a brain section containing the rostral end of the corpus callosum connecting two hemispheres to a brain section containing the posterior crus of the anterior commissure connecting two hemispheres.

\section{Microdialysis}

Microdialysis was carried out as previously described [21], with minor modifications. A guide cannula (AG-6, Eicom, Kyoto, Japan) was implanted into the frontal cortex $\left[15^{\circ}\right.$ angle, anteroposterior from the bregma, $+1.7 \mathrm{~mm}$ (P56 and P140), $+1.65 \mathrm{~mm}$ (P42), $+1.5 \mathrm{~mm}$ (P28); mediolateral from the bregma, $-1.0 \mathrm{~mm}$ (P56 and $\mathrm{P} 140),-0.9 \mathrm{~mm}$ (p42), $-0.6 \mathrm{~mm}$ (P28); dorsoventral from the dura, $-2.0 \mathrm{~mm}$ (P56 and P140), $-1.8 \mathrm{~mm}$ (P42), $-1.65 \mathrm{~mm}$ (P28)] according to the atlas of Paxinos and Franklin [19]. Ringer's solution (147 $\mathrm{mM} \mathrm{NaCl}, 4 \mathrm{mM} \mathrm{KCl}$, and $2.3 \mathrm{mM} \mathrm{CaCl}_{2}$ ) was perfused at a flow rate of $1.0 \mu \mathrm{l} / \mathrm{min}$. The samples were collected every $10 \mathrm{~min}$ from awake, freely moving mice and analyzed by an HPLC system (Eicom). Six samples were taken to establish the baseline measurement of extracellular glutamate. The levels of extracellular glutamate were analyzed after the intraperitoneal injection of MK-801 $(1 \mathrm{mg} / \mathrm{kg})$.

\section{Results}

To gain insights into the biological events during PFC development, we performed gene expression analysis by qRT-PCR, targeting representative genes for multiple neural components, namely, neurotransmitter receptors, synaptic components, GABAergic interneurons, and oligodendrocyte/myelin (table 1). We chose five postnatal time points: P7, P14 (two time points before weaning), P21 (weaning), P35 (adolescence), and P63 (adulthood).

\section{Glutamate Receptors and Synaptic Components in the} Developing PFC

Neurotransmitter receptors are central players for neurotransmission and critical for synaptic functions. We focused on two types of glutamate receptors, NMDAR and AMPAR, two major receptor types for excitatory synaptic transmissions. None of the AMPARs analyzed showed notable changes in their expressions during the course of development and maturation (fig. 1a). The NMDARs are heterotetrameric complexes comprised of two NR1 and two NR2 subunits; and among the NR2s, NR2A and NR2B are the predominant subunits expressed in the cortex. Grin1 showed a 4-fold reduction in its expression at P14 compared to P7 and stayed at this level, whereas Grin $2 a$ showed a 4 -fold increase in its expression at P14 and stayed at that level. Grin $2 b$ showed a gradual decrease in its expression, though not so drastically throughout development (fig. 1b). It has been observed that changes in the composition of NMDAR subunits, namely switching from NR2B to NR2A, take place at the early postnatal stage [22]. The gene expression patterns we observed may correspond to this switching event. Next, we characterized gene expression patterns for a neuromodulatory system, namely dopamine receptors (DRDs), which are targets of most antipsychotics effective for positive symptoms of schizophrenia [23]. Among the 5 DRDs, we could not detect sufficient amplification signals in the PFC for Drd3 which has been shown to be predominantly expressed in limbic regions of the brain [24]. Most of the DRDs analyzed showed a slight reduction in their expressions except $\operatorname{Drd} 4$ which showed a slight increase in its expression during development (fig. 1c).

We characterized several synaptic components as markers for synaptic development and maturation. Scaffolding proteins at the postsynaptic density (PSD) are crucial structural components, important for anchoring synaptic proteins like channels, receptors, and synaptic cell adhesion molecules (CAMs) [25]. We chose two representatives, Psd95 and Shank3, because recent findings have suggested that there might be differential synaptic localizations of these molecules, at least in humans [26]. Fmr1 and Cyfip1 are important translational modulators at synapses whose alterations are associated with developmental neuropsychiatric disorders [27]. All these 4 genes did not show any notable differences at all 5 time points (fig. 1d). CAMs are key players for supporting synaptic connections [28] and are also involved in neuronglial interactions, e.g., myelination [29]. Most of the CAMs analyzed did not show drastic changes in the expressions during the development of the PFC except Cntnap1 which plays a role in the formation of myelinated nerve structures [30]. Cntnap1 increased its expression at P14 by 4 fold compared to P7 and gradually increased its expression thereafter (fig. 1e).

\section{GABAergic Inhibitory Interneurons in the Developing PFC}

GABAergic inhibitory interneurons are essential components for local circuitry. Proper excitatory/inhibitory balance, determined by the activities of excitatory and inhibitory neurons, is crucial for regulating an activity of
Ueda/Niwa/Hioki/Sohn/Kaneko/Sawa/ Sakurai 
Fig. 1.Gene expression profiles in the developing PFC. a AMPARs, b NMDARs, c DRDs, d PSD molecules, e CAMs, $\mathbf{f}$ interneuron-related genes, and $\mathbf{g}$ oligodendrocyte/myelin-related genes (see table 1). The endogenous control gene, Gapdh, was used for normalization. Data are the means of three independent samples for each point.
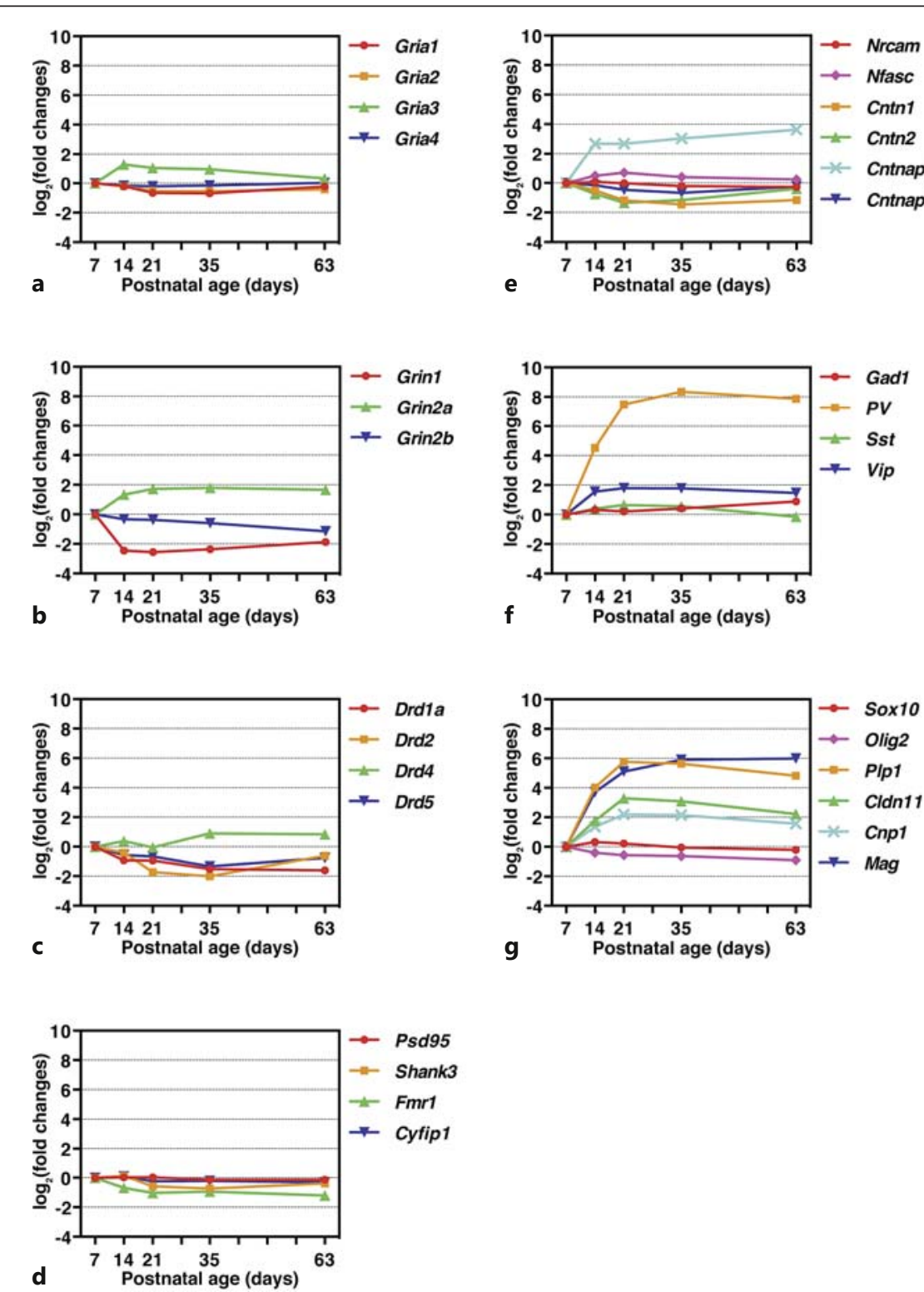

the local circuitry that serves as a module in the neuronal networks, necessary for higher brain functions [e.g., 31, 32]. Although all of these interneuron populations share a common character, i.e., use GABA as their neurotransmitter, they are comprised of diverse groups of neurons. Recent studies have classified GABAergic interneurons based on morphology, molecular profiling, and electrical properties into 3 major subclasses such as PV-positive fast-spiking neurons, somatostatin (Sst)-positive burstspiking neurons, and vasoactive intestinal peptide (Vip)positive regular-spiking neurons [33]. When we charac- terized the expression of the glutamate decarboxylase 1 ( Gad1) gene, a marker gene for all GABAergic interneurons, we did not detect dynamic changes during development. However, when we analyzed the cell type-specific profiles, we found quite different pictures. The expression of the $P V$ gene was drastically increased between P7 and P21 (about 256 fold) and reached its peak level at P35. The Vip gene showed a 4-fold increase between P7 and P21, and peaked at P35. The Sst gene did not show drastic changes (fig. 1f). These data suggest that the appearance of the PV-positive neurons in the PFC drastically increas- 


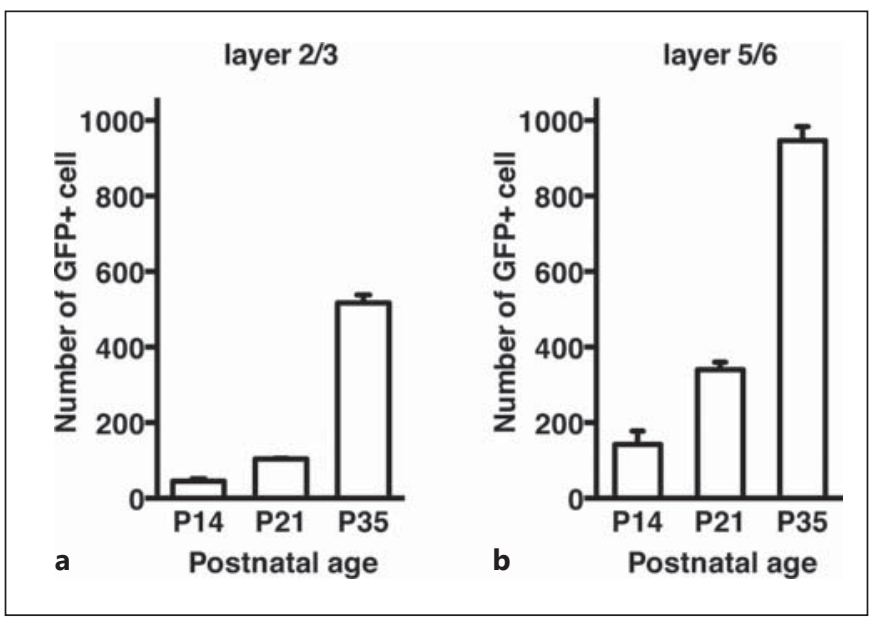

Fig. 2.Appearance of PV-positive cells in the developing PFC. The total number of GFP-positive (GFP+) cells in layer 2/3 (a) and layer 5/6 (b) of the anterior cingulate cortex (area 24) of PV/ myrGFP-LDLRct mice that express GFP under the $P V$ gene promoter were counted as described in Materials and Methods. Data are the means \pm SEM of two independent samples for each point.

es between P7 and P21. To confirm this, we analyzed transgenic mice expressing myristoylated GFP under the promoter of the $P V$ gene. The PV-positive interneurons comprised of basket cells and chandelier cells are localized in the upper (layer 2/3) and lower (layer 5/6) layers in the mouse PFC. Consistent with the gene expression data above, the total number of GFP-positive cells increased between P21 and P35 in both layer 2/3 and 5/6 in the PFC (fig. 2).

\section{Myelin and Oligodendrocytes in the Developing PFC}

A local circuitry on its own serves as a module that needs to be connected with other modules spread over the brain in order to function in the networks. This is achieved by long projections connecting among these modules. This configuration is the basis for neural networks that are crucial for behavioral tasks [34]. Long projections support a fast neural transmission along the pathways to ensure proper information processing through networks, which is achieved by their myelination by oligodendrocytes [35]. Transmitted signals through the myelinated long projections affect the nature of inputs to the local circuitry, modulating the maturation of the local circuitry's activity; and, therefore, myelination/oligodendrocyte development in the PFC must be correlated with the maturation processes of the PFC. We characterized expression profiles of several oligodendrocyte/myelin-related genes in the developing PFC. Two transcription factors,
Olig2 and Sox10, controlling the differentiation of oligodendrocytes $[36,37]$ did not show significant changes. However, myelin components, such as Plp1 and Mag, showed drastic increases (64 fold) between P7 and P21 and reached their peak level at P21. Other components important for the formation of the myelinated nerve structure, such as Cldn11 and Cnp1, also showed increases (4-8 fold) with a similar time course (fig. $1 \mathrm{~g}$ ).

\section{MK-801 Sensitivity of the Developing PFC}

The results above suggest that PFC maturation may continue at least till P35, when the $P V$ gene expression reaches the maximum level. The systemic administration of an NMDAR antagonist, MK-801, increases the glutamate efflux in the PFC [38], and the sensitivity to NMDAR antagonists is thought to reflect physiological properties of the neural circuitry [e.g., 39]. Therefore, to clarify the timing of the functional maturation of the PFC, we investigated the responsiveness to the administration of MK- 801 by measuring the extracellular glutamate level in mouse PFC using in vivo microdialysis. We analyzed four different time points: P28, P42, P56 (three time points during adolescence), and P140 (adulthood). The level of extracellular glutamate was lower at P28 compared to the adult level, but reached a similar level to that in adult by $\mathrm{P} 42$ (data not shown). However, the response of glutamate release to the administration of MK-801 was more exaggerated at $\mathrm{P} 42$ than the response in adult. At P56, the response became similar to the one at P140 (fig. 3). These results suggest that functional circuitry maturation in the PFC involving a NMDAR may be achieved by $\mathrm{P} 56$, far beyond $\mathrm{P} 42$.

\section{Gene Expression Patterns during the Postnatal \\ Development of the Striatum}

Since the striatum is another place that is presumed to be affected in developmental neuropsychiatric disorders like schizophrenia [40], it was of interest to compare developing patterns in the striatum to the ones in the PFC. We performed the same gene expression analyses using mouse striatum during the same time periods as above. The patterns of AMPARs, NMDARs, and synaptic components were more or less the same as the ones observed in the PFC (fig. 4a, b, and d). The DRDs showed similar patterns except Drd4 which showed a more pronounced reduction at P21 (fig. 4c). The CAMs also showed similar trends of the expression changes (though there were some quantitative differences) during development (fig. 4e). However, the expression of the interneuron genes showed quite different patterns. There were 16-fold increases
Ueda/Niwa/Hioki/Sohn/Kaneko/Sawa/ Sakurai 
Fig. 3. Measurement of extracellular glutamate in the frontal cortex. The changes in the extracellular glutamate level after the administration of MK-801 were monitored by in vivo microdialysis. Data are means \pm SEM ( $\mathrm{n}=10-14$ for each group). Statistical significance was determined using oneway ANOVA and subsequent Fisher's PLSD for multiple comparisons. ${ }^{* *} \mathrm{p}<$ 0.01 .

Fig. 4. Gene expression profiles in the developing striatum. a AMPARs, b NMDARs, c DRDs, d PSD molecules, e CAMs, f interneuron-related genes, and $\mathbf{g}$ oligodendrocyte/myelin-related genes (see table 1). The endogenous control gene, Gapdh, was used for normalization. Data are the means of three independent samples for each point.
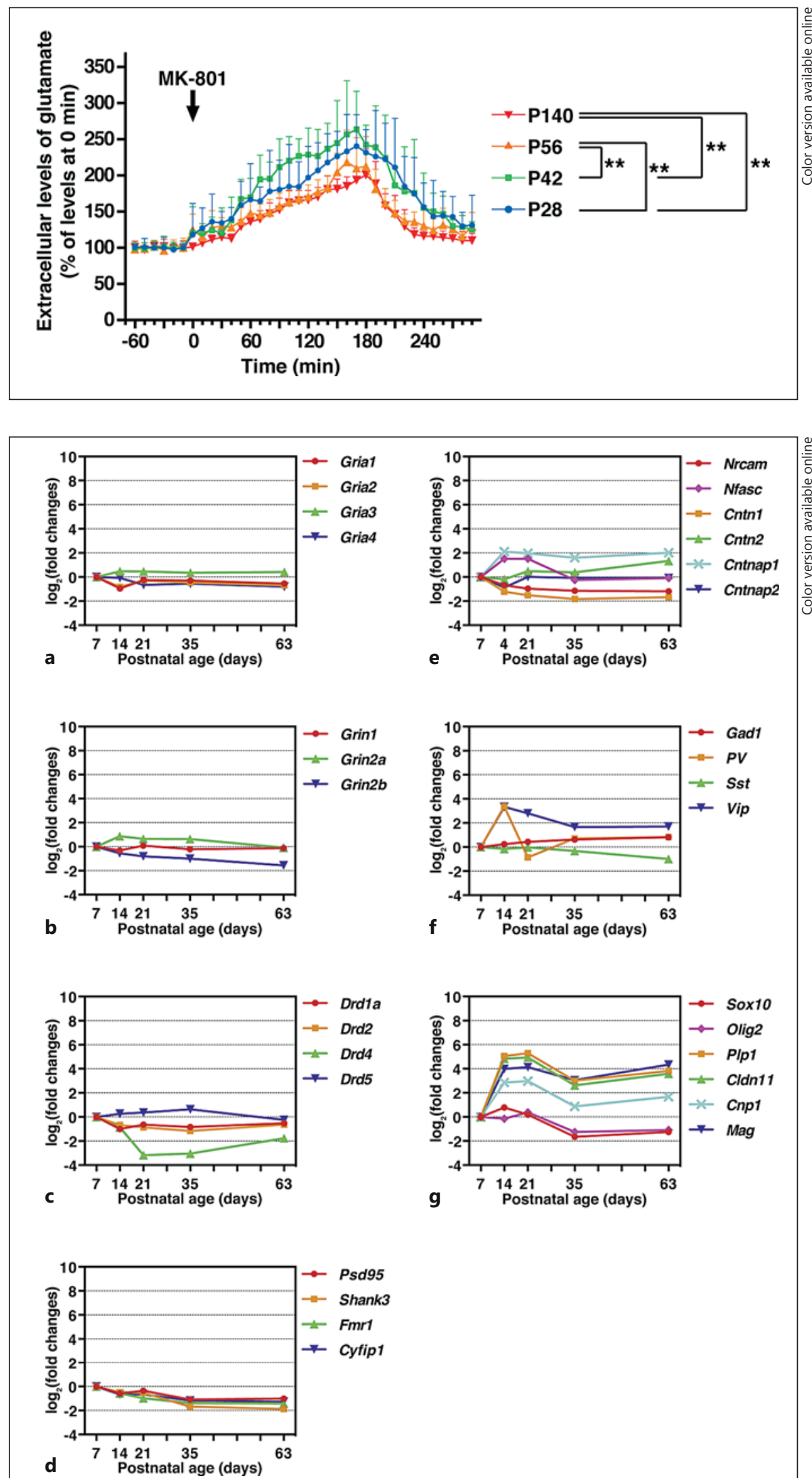
both in the $P V$ and Vip gene expressions between P7 and $\mathrm{P} 14$, but the expressions decreased thereafter (fig. 4f). Furthermore, the oligodendrocyte/myelin-related genes showed quite distinct patterns from those in the PFC. Whereas Olig2 and Sox10 showed similar patterns to the ones in the PFC, genes such as Plp1, Mag, Cldn11, and Cnp1 increased in their expressions and reached their maximum levels by P14 (fig. 4g).

These results implicate that expression changes during development show regional differences, and that the PFC seems to have a slower time course of maturation than the striatum, based on the expression of interneuron and myelin-related genes. It has been shown that neuronal maturation as well as myelination in the human PFC is slower compared to any other brain region [41, 42]. Our data support that this may be applied to the rodent PFC as well.

\section{Discussion}

Developmental neuropsychiatric disorders such as schizophrenia show impairments in cognitive functions that are mediated by the PFC (e.g., working memory [43]). The developmental processes of the PFC may be affected by a combination of genetic and environmental factors, serving as biological bases for pathogenesis of the disorder $[8,44]$. The establishment of functional neural circuits requires temporally coordinated, multiple biological processes, including neurogenesis, the migration of newborn neurons, neurite outgrowth, gliogenesis, synaptogenesis, myelination, and synapse maturation/elimination [45]. In the present study, we focused on the processes taking place postnatally, namely synaptogenesis, activity-dependent synaptic modulation, the development of neuromodulation (dopamine), and myelination during the development and maturation of the PFC, focusing on processes relevant to pathophysiology of the disorders.

\section{Gene Expression Profiles in the Developing PFC}

Neuronal activity in the local circuitry depends on glutamatergic neurons. It has been shown that during maturation there is a subunit switch in NR2 components, namely NR2A and NR2B [22]. We detected changes in the expression of genes for these subunits at early postnatal ages that may reflect this subunit switch. However, at P14, the glutamate receptors already showed similar expression patterns to the ones in the mature brain.

Cognitive functions involving the local circuitry require maintaining appropriate excitatory/inhibitory balance [e.g., 46], in which GABAergic interneurons play crucial roles. In the present study, individual GABAergic interneuron populations showed distinct patterns of the gene expression profile. Especially, the $P V$ gene showed a unique pattern, drastically increasing its expression with a peak at $\mathrm{P} 35$. The maturation of PV neurons depends on appropriate inputs from pyramidal neurons [47], a process dependent on NMDARs on the PV neurons [48]. These data imply that the maturation of the PV neurons is correlated with local circuitry maturation. Local circuitry maturation in turn should be correlated with functional measurements of the PFC, such as gamma oscillation [49]. Altered gamma oscillation is reported in schizophrenia [32], possibly underscoring the importance of maturation of the PV neurons in schizophrenia pathogenesis.

When we characterized the expression patterns of the oligodendrocyte/myelin-related genes, we found that the Mag and Plp1 genes, whose products are directly involved in myelin sheath formation, notably increased in their expressions during the development of the PFC. It has been shown that the degree of myelination depends on the neuronal activity of the axons that are wrapped by oligodendrocytes [50]. These data support the idea that maturation of neuronal activity in the PFC circuits induces maturation of myelination of the PFC neurons. In addition, the degree of myelination should also affect maturation of the local circuitry's activity, having bidirectional interactions. A recent report demonstrating that complicated motor skill learning requires active central myelination in the corpus callosum in adults [51] has underscored the importance of myelination in maturation of brain functions.

When we characterized the extracellular glutamate level in the PFC, we observed a similar level already at P42 to adulthood. However, the response of glutamate release in the frontal cortex to the systemic administration of MK-801 was still exaggerated at P28 and P42, and became similar to the adult level at P56. This suggests that although gene expression patterns of glutamate and inhibitory neurons as well as myelination become similar to the adult ones at P35, the circuitry is still functionally immature. At this moment, we do not know what correlates with this time period that is vulnerable to MK-801, gene expression wise, but possible candidates of biological processes taking place during this late maturation period would be ongoing synaptic pruning, the functional maturation of inhibitory neurons, and/or the maturation of neuromodulation such as the dopamine system.

Behaviorally, mice exhibit developmental milestones reflecting the acquisition/disappearance of different abil- 
ities/tendencies at certain ages that have been described in many behavioral tasks such as novel object recognition tasks [52]. At P21, mice demonstrate object exploration comparable to adults, but they are unable to detect either object rearrangement or object novelty. At P28, mice show higher locomotion activity and object exploration and are able to detect the spatial rearrangement, though they do not display preference for the displaced objects (which adult mice would do). They also clearly react to object novelty. At P49 (which is equivalent to adolescence), mice show the highest levels of object exploration and are able to detect spatial rearrangement, but they still do not display any preference for the displaced objects. They also react to object novelty. Although spatial learning is mediated by the hippocampus, some of these features may also be associated with PFC development. Moreover, it has been shown that at P42-P56, mice can perform well in Y-maze and object-based attention tests [53], supporting the idea that abilities of working memory and attention, features mediated by the PFC, are established around this time period.

As for social behavior, another brain function involving the PFC, adults are mainly concerned with dominance/submission and reproductive matters, spending most of their social time in patrolling, fighting, copulating, and raising litters. However, developing mice (namely at P21-P45) engage in frequent and prolonged bouts of amicable and playful behavior [54]. This complex and subtle domain of social activity seems to have a prominent role in the development and refinement of species-specific behavioral repertoire (from motor to cognitive and social skills) [54]. The development of some of these social behaviors may also be associated with PFC development.

When we compared gene expression profiles of the developing PFC with those of the developing striatum, the timing of the peaks was different for the interneuron and myelin genes (compare fig. 1 and 4). Furthermore, even in the cerebral cortex, the patterns seemed to be different from the ones in the motor and sensory cortices (unpubl. results). These results suggest that the PFC has unique developmental profiles of gene expression, perhaps reflecting a different timing of the maturation of biological processes.

Gene Expression and Functional Outcomes: Molecular Targets for Translation

The gene expression profiles can be used as molecular signatures of biological processes during PFC development. Many mouse models with modified genes that are associated with developmental neuropsychiatric disor- ders like autism and schizophrenia have been developed and characterized. Analyses of the PFC in those mice showed a wide range of changes including synaptic dysfunction, decreased PV interneurons, alterations in the excitatory/inhibitory balance, and myelination deficits [e.g., 20, 55-63]. Using the molecular signatures described here, it will become possible for us to identify pathological chains of events introduced in those animals, which may lead to behavioral alterations, namely cognitive deficits. Once we identify critical biological events that are affected in these mouse models, we could devise therapeutic approaches to correct those biological events, by which we may be able to improve behavioral deficits [e.g., 64-69].

Interestingly, the onset of schizophrenia in humans is usually in the late teens and early twenties. It is believed that during adolescence, the brain receives impacts from environmental insults, resulting in a dysfunction in the system that manifests as psychosis episodes (the onset of the disorders). In the case of mice, adolescence corresponds to the time period from weaning to adulthood (P28-P56). The PFC shows an extended period sensitive to the detrimental effects of stress exposure [70], and our data suggest that the time window for environmental insults to the PFC remains open at least till P56 in mice. It has been shown that social isolation during P21-P35 affected PFC myelination and induced behavioral alterations, whereas social isolation during P35-P56 did not affect PFC myelination nor did it induce those behavioral alterations observed in the former isolation condition [71]. Interestingly, social isolation during P35-P56 affected the gene expression patterns in the mesocortical system, but not in the mesolimbic dopaminergic system through the hypothalamic-pituitary-adrenal (HPA) axis, i.e., stress response, and showed behavioral alterations in different domains [21]. The former time period corresponds to the period of myelin maturation (P21-P35), whereas the latter time period corresponds to the period of late circuitry maturation predicted in this study (P35P56). This suggests that different insults (combined with different time periods) may affect different biological processes during PFC maturation, which may lead to different behavioral phenotypes.

Recently, the prodromal period of schizophrenia has been identified, in which impaired brain circuitry and functions are present before the onset of the disease [72, 73]. By identifying critical changes in the brain during the prodromal period, we could develop early interventions to prevent the onset of the disorders, i.e., psychosis. Longitudinal studies using brain imaging showed that popu- 
lations at high risk for schizophrenia developed progressive brain volume loss over time [74-76], which may be used as indicators for early interventions in these populations. There are numerous studies using brain imaging, trying to pinpoint the biological nature of these events [e.g., 77]. It would be necessary to characterize both preclinical and clinical models in parallel [17], and by characterizing the animal models along the developmental trajectory of the PFC described here, we should be able to clarify the molecular signatures of prodromal phenotypes that may be translated into humans as useful biomarkers.

\section{Conclusion}

We have provided basic information of molecular profiles in the developing mouse PFC that may correlate with the maturation level of the brain region. Compared with similar information identified in primates [e.g., 78, 79], the results provided here in mice should be useful when we characterize the PFC of mouse models for developmental neuropsychiatric disorders in order to understand pathophysiology of the disorders as well as the biological nature of the prodromal state of schizophrenia.

\section{Acknowledgements}

Our work, performed at the Open Innovation Laboratory for Drug Discovery and Development by Takeda and Kyoto University's 'Basic and Clinical Research Project for CNS Drugs', was supported in part by Takeda Pharmaceutical Co. Ltd. In addition, A.S. and M.N. are supported by the NIH (MH-084018, MH-094268 Silvio O. Conte Center, MH-069853, MH-085226, MH-088753, and MH-092443 to A.S.; K99MH-094408 to M.N.) and T.S., H.H., J.S., and T.K. are supported by grants from the Ministry of Education, Culture, Sports, Science and Technology in Japan/Japan Society for the Promotion of Science Grants-in-Aid for Scientific Research (25116516 and 25350987 to T.S.; 25123709,22110007 , and 24500408 to H.H.; $13 J 01992$ to J.S.; 23115101 and 25250006 to T.K.). J.S. is a Research Fellow of the Japan Society for the Promotion of Science. We thank the Medical Research Support Center at Kyoto University Graduate School of Medicine for the fluorescence microscopy (supported by Platform for Drug Discovery, Informatics, and Structural Life Science from the Ministry of Education, Culture, Sports, Science and Technology in Japan) and Drs. Hikida and Tomoda of the Medical Innovation Center for critical reading and comments.

\section{Disclosure Statement}

The authors declare that there are no conflicts of interest regarding this article.

\section{References}

1 Fuster JM: The Prefrontal Cortex, ed 4. Amsterdam, Elsevier, 2008.

-2 Giedd JN: Structural magnetic resonance imaging of the adolescent brain. Ann NY Acad Sci 2004;1021:77-85.

3 Raznahan A, Lerch JP, Lee N, Greenstein D, Wallace GL, Stockman M, Clasen L, Shaw PW, Giedd JN: Patterns of coordinated anatomical change in human cortical development: a longitudinal neuroimaging study of maturational coupling. Neuron 2011;72:873884.

4 Miller DJ, Duka T, Stimpson CD, Schapiro SJ, Baze WB, McArthur MJ, Fobbs AJ, Sousa AM, Sestan N, Wildman DE, Lipovich L, Kuzawa CW, Hof PR, Sherwood CC: Prolonged myelination in human neocortical evolution. Proc Natl Acad Sci USA 2012;109:1648016485.

$\checkmark 5$ Catts VS, Fung SJ, Long LE, Joshi D, Vercammen A, Allen KM, Fillman SG, Rothmond DA, Sinclair D, Tiwari Y, Tsai SY, Weickert TW, Shannon Weickert C: Rethinking schizophrenia in the context of normal neurodevelopment. Front Cell Neurosci 2013;7:60.

6 Kahn RS, Keefe RS: Schizophrenia is a cognitive illness: time for a change in focus. JAMA Psychiatry 2013;70:1107-1112.
7 Weinberger DR: On the plausibility of 'the neurodevelopmental hypothesis' of schizophrenia. Neuropsychopharmacology 1996; 14:1S-11S.

8 Insel TR: Rethinking schizophrenia. Nature 2010;468:187-193.

-9 Lieberman JA: Neurobiology and the natural history of schizophrenia. J Clin Psychiatry 2006;67:e14.

10 Weinberger DR, Harrison PJ: Schizophrenia, ed 3. Chichester, Wiley-Blackwell, 2011.

11 Hall J, Trent S, Thomas KL, O’Donovan MC, Owen MJ: Genetic risk for schizophrenia: convergence on synaptic pathways involved in plasticity. Biol Psychiatry 2015;77:52-58.

$\checkmark 12$ Schizophrenia Working Group of the Psychiatric Genomics Consortium: Biological insights from 108 schizophrenia-associated genetic loci. Nature 2014;511:421-427.

13 De Rubeis S, He X, Goldberg AP, et al: Synaptic, transcriptional and chromatin genes disrupted in autism. Nature 2014;515:209-215.

14 Young JW, Zhou X, Geyer MA: Animal models of schizophrenia. Curr Top Behav Neurosci 2010;4:391-433.
15 Kas MJ, Glennon JC, Buitelaar J, Ey E, Biemans B, Crawley J, Ring RH, Lajonchere C, Esclassan F, Talpos J, Noldus LP, Burbach JP, Steckler T: Assessing behavioural and cognitive domains of autism spectrum disorders in rodents: current status and future perspectives. Psychopharmacology (Berl) 2014;231: $1125-1146$

16 Silverman JL, Yang M, Lord C, Crawley JN: Behavioural phenotyping assays for mouse models of autism. Nat Rev Neurosci 2010;11: 490-502.

17 Sawa A, Seidman LJ: Is prophylactic psychiatry around the corner? Combating adolescent oxidative stress for adult psychosis and schizophrenia. Neuron 2014;83:991-993.

-18 Kameda H, Hioki H, Tanaka YH, Tanaka T, Sohn J, Sonomura T, Furuta T, Fujiyama F, Kaneko T: Parvalbumin-producing cortical interneurons receive inhibitory inputs on proximal portions and cortical excitatory inputs on distal dendrites. Eur J Neurosci 2012; 35:838-854.

19 Paxinos G, Franklin KBJ: Paxinos and Franklin's the Mouse Brain in Stereotaxic Coordinates, ed 4. London, Academic Press, 2013. 
20 Takahashi N, Sakurai T, Bozdagi-Gunal O, Dorr NP, Moy J, Krug L, Gama-Sosa M, Elder GA, Koch RJ, Walker RH, Hof PR, Davis KL, Buxbaum JD: Increased expression of receptor phosphotyrosine phosphatase-beta/zeta is associated with molecular, cellular, behavioral and cognitive schizophrenia phenotypes. Transl Psychiatry 2011;1:e8.

-21 Niwa M, Jaaro-Peled H, Tankou S, Seshadri S, Hikida T, Matsumoto Y, Cascella NG, Kano S, Ozaki N, Nabeshima T, Sawa A: Adolescent stress-induced epigenetic control of dopaminergic neurons via glucocorticoids. Science 2013;339:335-339.

22 Liu XB, Murray KD, Jones EG: Switching of NMDA receptor $2 \mathrm{~A}$ and $2 \mathrm{~B}$ subunits at thalamic and cortical synapses during early postnatal development. J Neurosci 2004;24:88858895.

23 Miyamoto S, Miyake N, Jarskog LF, Fleischhacker WW, Lieberman JA: Pharmacological treatment of schizophrenia: a critical review of the pharmacology and clinical effects of current and future therapeutic agents. Mol Psychiatry 2012;17:1206-1227.

24 Sokoloff P, Giros B, Martres MP, Bouthenet ML, Schwartz JC: Molecular cloning and characterization of a novel dopamine receptor (D3) as a target for neuroleptics. Nature 1990;347:146-151.

-25 Nithianantharajah J, Komiyama NH, McKechanie A, Johnstone M, Blackwood DH, St Clair D, Emes RD, van de Lagemaat $\mathrm{LN}$, Saksida LM, Bussey TJ, Grant SG: Synaptic scaffold evolution generated components of vertebrate cognitive complexity. Nat Neurosci 2013;16:16-24.

-26 Shcheglovitov A, Shcheglovitova O, Yazawa M, Portmann T, Shu R, Sebastiano V, Krawisz A, Froehlich W, Bernstein JA, Hallmayer JF, Dolmetsch RE: SHANK3 and IGF1 restore synaptic deficits in neurons from 22q13 deletion syndrome patients. Nature 2013;503: 267-271.

27 Fernandez E, Rajan N, Bagni C: The FMRP regulon: from targets to disease convergence. Front Neurosci 2013;7:191.

28 Bukalo O, Dityatev A: Synaptic cell adhesion molecules. Adv Exp Med Biol 2012;970:97128.

29 Poliak S, Peles E: The local differentiation of myelinated axons at nodes of Ranvier. Nat Rev Neurosci 2003;4:968-980.

- 30 Bhat MA, Rios JC, Lu Y, Garcia-Fresco GP, Ching W, St Martin M, Li J, Einheber S, Chesler M, Rosenbluth J, Salzer JL, Bellen HJ: Axon-glia interactions and the domain organization of myelinated axons requires neurexin IV/Caspr/Paranodin. Neuron 2001;30: 369-383.

-31 Takesian AE, Hensch TK: Balancing plasticity/stability across brain development. Prog Brain Res 2013;207:3-34.

- 32 Uhlhaas PJ, Singer W: High-frequency oscillations and the neurobiology of schizophrenia. Dialogues Clin Neurosci 2013;15:301-313.
3 Kepecs A, Fishell G: Interneuron cell types are fit to function. Nature 2014;505:318-326.

34 van den Heuvel MP, Fornito A: Brain networks in schizophrenia. Neuropsychol Rev 2014;24:32-48.

-35 Nave KA: Myelination and support of axonal integrity by glia. Nature 2010;468:244-252.

36 Lu QR, Yuk D, Alberta JA, Zhu Z, Pawlitzky I, Chan J, McMahon AP, Stiles CD, Rowitch DH: Sonic hedgehog - regulated oligodendrocyte lineage genes encoding bHLH proteins in the mammalian central nervous system. Neuron 2000;25:317-329.

- 37 Stolt CC, Rehberg S, Ader M, Lommes P, Riethmacher D, Schachner M, Bartsch U, Wegner M: Terminal differentiation of myelin-forming oligodendrocytes depends on the transcription factor Sox10. Genes Dev 2002;16:165-170.

38 Bubser M, Tzschentke T, Hauber W: Behavioural and neurochemical interactions of the AMPA antagonist GYKI 52466 and the noncompetitive NMDA antagonist dizocilpine in rats. J Neural Transm Gen Sect 1995; 101:115126.

39 Gonzalez-Burgos G, Kroener S, Zaitsev AV, Povysheva NV, Krimer LS, Barrionuevo G, Lewis DA: Functional maturation of excitatory synapses in layer 3 pyramidal neurons during postnatal development of the primate prefrontal cortex. Cereb Cortex 2008;18:626637.

40 Simpson EH, Kellendonk C, Kandel E: A possible role for the striatum in the pathogenesis of the cognitive symptoms of schizophrenia Neuron 2010;65:585-596.

-41 Petanjek Z, Judas M, Simic G, Rasin MR, Uylings HB, Rakic P, Kostovic I: Extraordinary neoteny of synaptic spines in the human prefrontal cortex. Proc Natl Acad Sci USA 2011;108:13281-13286.

42 Hoistad M, Segal D, Takahashi N, Sakurai T, Buxbaum JD, Hof PR: Linking white and grey matter in schizophrenia: oligodendrocyte and neuron pathology in the prefrontal cortex. Front Neuroanat 2009;3:9.

43 Goldman-Rakic PS: Working memory dysfunction in schizophrenia. J Neuropsychiatry Clin Neurosci 1994;6:348-357.

44 Jaaro-Peled H, Hayashi-Takagi A, Seshadri S, Kamiya A, Brandon NJ, Sawa A: Neurodevelopmental mechanisms of schizophrenia: understanding disturbed postnatal brain maturation through neuregulin-1-ErbB4 and DISC1. Trends Neurosci 2009;32:485-495.

45 Kandel ER, Schwartz JH, Jessell TM, Siegelbaum SA, Hudspeth AJ: Principles of Neural Science, ed 5. New York, McGraw-Hill Professional, 2012.

46 Yizhar O, Fenno LE, Prigge M, Schneider F, Davidson TJ, O'Shea DJ, Sohal VS, Goshen I, Finkelstein J, Paz JT, Stehfest K, Fudim R, Ramakrishnan C, Huguenard JR, Hegemann P, Deisseroth K: Neocortical excitation/inhibition balance in information processing and social dysfunction. Nature 2011;477:171-178.
47 Huang ZJ, Kirkwood A, Pizzorusso T, Porciatti V, Morales B, Bear MF, Maffei L, Tonegawa $S$ : BDNF regulates the maturation of inhibition and the critical period of plasticity in mouse visual cortex. Cell 1999;98:739-755.

48 Carlen M, Meletis K, Siegle JH, Cardin JA, Futai K, Vierling-Claassen D, Ruhlmann C, Jones SR, Deisseroth K, Sheng M, Moore CI, Tsai LH: A critical role for NMDA receptors in parvalbumin interneurons for gamma rhythm induction and behavior. Mol Psychiatry 2012;17:537-548.

49 Curley AA, Lewis DA: Cortical basket cell dysfunction in schizophrenia. J Physiol 2012; 590:715-724.

50 Wake H, Lee PR, Fields RD: Control of local protein synthesis and initial events in myelination by action potentials. Science 2011;333: 1647-1651.

51 McKenzie IA, Ohayon D, Li H, de Faria JP Emery B, Tohyama K, Richardson WD: Motor skill learning requires active central myelination. Science 2014;346:318-322.

52 Ricceri L, Colozza C, Calamandrei G: Ontogeny of spatial discrimination in mice: a longitudinal analysis in the modified open-field with objects. Dev Psychobiol 2000;37:109118

53 Alkam T, Kim HC, Mamiya T, Yamada K, Hiramatsu M, Nabeshima T: Evaluation of cognitive behaviors in young offspring of C57BL/6 J mice after gestational nicotine exposure during different time-windows. Psychopharmacology (Berl) 2013;230:451-463.

54 Terranova ML, Laviola G: Scoring of social interactions and play in mice during adolescence. Curr Protoc Toxicol 2005; Chapter 13:Unit13.10

55 Del Pino I, Garcia-Frigola C, Dehorter N, Brotons-Mas JR, Alvarez-Salvado E, Martinez de Lagran M, Ciceri G, Gabaldon MV, Moratal D, Dierssen M, Canals S, Marin O, Rico $\mathrm{B}$ : Erbb4 deletion from fast-spiking interneurons causes schizophrenia-like phenotypes. Neuron 2013;79:1152-1168.

56 Fenelon K, Xu B, Lai CS, Mukai J, Markx S, Stark KL, Hsu PK, Gan WB, Fischbach GD, MacDermott AB, Karayiorgou M, Gogos JA: The pattern of cortical dysfunction in a mouse model of a schizophrenia-related microdeletion. J Neurosci 2013;33:14825-14839.

57 Yin DM, Sun XD, Bean JC, Lin TW, Sathyamurthy A, Xiong WC, Gao TM, Chen YJ, Mei L: Regulation of spine formation by ErbB4 in PV-positive interneurons. J Neurosci 2013;33:19295-19303.

58 Yin DM, Chen YJ, Lu YS, Bean JC, Sathyamurthy A, Shen C, Liu X, Lin TW, Smith CA, Xiong WC, Mei L: Reversal of behavioral deficits and synaptic dysfunction in mice overexpressing neuregulin 1. Neuron 2013;78:644657.

59 Karayannis T, Au E, Patel JC, et al: Cntnap4 differentially contributes to GABAergic and dopaminergic synaptic transmission. Nature 2014;511:236-240. 
60 Bissonette GB, Bae MH, Suresh T, Jaffe DE, Powell EM: Prefrontal cognitive deficits in mice with altered cerebral cortical GABAergic interneurons. Behav Brain Res 2014;259: 143-151.

61 Bissonette GB, Schoenbaum G, Roesch MR, Powell EM: Interneurons are necessary for coordinated activity during reversal learning in orbitofrontal cortex. Biol Psychiatry 2015; 77:454-464.

62 Penagarikano O, Abrahams BS, Herman EI, Winden KD, Gdalyahu A, Dong H, Sonnenblick LI, Gruver R, Almajano J, Bragin A, Golshani P, Trachtenberg JT, Peles E, Geschwind DH: Absence of CNTNAP2 leads to epilepsy, neuronal migration abnormalities, and core autism-related deficits. Cell 2011;147:235246.

63 Krueger DD, Osterweil EK, Chen SP, Tye LD, Bear MF: Cognitive dysfunction and prefrontal synaptic abnormalities in a mouse model of fragile X syndrome. Proc Natl Acad Sci USA 2011;108:2587-2592.

-64 Hayashi-Takagi A, Araki Y, Nakamura M, Vollrath B, Duron SG, Yan Z, Kasai H, Huganir RL, Campbell DA, Sawa A: PAKs inhibitors ameliorate schizophrenia-associated dendritic spine deterioration in vitro and in vivo during late adolescence. Proc Natl Acad Sci USA 2014;111:6461-6466.

-65 Cabungcal JH, Counotte DS, Lewis EM, Tejeda HA, Piantadosi P, Pollock C, Calhoon GG, Sullivan EM, Presgraves E, Kil J, Hong LE, Cuenod M, Do KQ, O’Donnell P: Juvenile antioxidant treatment prevents adult deficits in a developmental model of schizophrenia. Neuron 2014;83:1073-1084.
66 Tang G, Gudsnuk K, Kuo SH, Cotrina ML, Rosoklija G, Sosunov A, Sonders MS, Kanter E, Castagna C, Yamamoto A, Yue Z, Arancio $\mathrm{O}$, Peterson BS, Champagne F, Dwork AJ, Goldman J, Sulzer D: Loss of mTOR-dependent macroautophagy causes autistic-like synaptic pruning deficits. Neuron 2014;83: 1131-1143.

67 Penagarikano O, Lazaro MT, Lu XH, Gordon A, Dong H, Lam HA, Peles E, Maidment NT, Murphy NP, Yang XW, Golshani P, Geschwind DH: Exogenous and evoked oxytocin restores social behavior in the Cntnap2 mouse model of autism. Sci Transl Med 2015; 7:271ra8.

68 Krueger DD, Bear MF: Toward fulfilling the promise of molecular medicine in fragile $\mathrm{X}$ syndrome. Annu Rev Med 2011;62:411-429.

69 Sahin M: Targeted treatment trials for tuberous sclerosis and autism: no longer a dream. Curr Opin Neurobiol 2012;22:895-901.

70 Arnsten A, Mazure CM, Sinha R: This is your brain in meltdown. Sci Am 2012;306:48-53.

71 Makinodan M, Rosen KM, Ito S, Corfas G: A critical period for social experience-dependent oligodendrocyte maturation and myelination. Science 2012;337:1357-1360.

72 Yung AR, McGorry PD: The prodromal phase of first-episode psychosis: past and current conceptualizations. Schizophr Bull 1996; 22:353-370.

73 Seidman LJ, Giuliano AJ, Meyer EC, et al: Neuropsychology of the prodrome to psychosis in the NAPLS consortium: relationship to family history and conversion to psychosis. Arch Gen Psychiatry 2010;67:578-588.
74 Dazzan P, Soulsby B, Mechelli A, Wood SJ, Velakoulis D, Phillips LJ, Yung AR, Chitnis X, Lin A, Murray RM, McGorry PD, McGuire PK, Pantelis C: Volumetric abnormalities predating the onset of schizophrenia and affective psychoses: an MRI study in subjects at ultrahigh risk of psychosis. Schizophr Bull 2012;38:1083-1091.

75 Brans RG, van Haren NE, van Baal GC, Staal WG, Schnack HG, Kahn RS, Hulshoff Pol HE: Longitudinal MRI study in schizophrenia patients and their healthy siblings. Br J Psychiatry 2008; 193:422-423.

76 van Haren NE, Hulshoff Pol HE, Schnack HG, Cahn W, Brans R, Carati I, Rais M, Kahn RS: Progressive brain volume loss in schizophrenia over the course of the illness: evidence of maturational abnormalities in early adulthood. Biol Psychiatry 2008;63:106-113.

-77 Fusar-Poli P, Howes OD, Allen P, Broome M, Valli I, Asselin MC, Grasby PM, McGuire PK: Abnormal frontostriatal interactions in people with prodromal signs of psychosis: a multimodal imaging study. Arch Gen Psychiatry 2010;67:683-691.

78 Hoftman GD, Volk DW, Bazmi HH, Li S, Sampson AR, Lewis DA: Altered cortical expression of GABA-related genes in schizophrenia: illness progression vs developmental disturbance. Schizophr Bull 2015;41:180191.

79 Hoftman GD, Lewis DA: Postnatal developmental trajectories of neural circuits in the primate prefrontal cortex: identifying sensitive periods for vulnerability to schizophrenia. Schizophr Bull 2011;37:493-503. 